\title{
Sulfur isotopic fractionation among sphalerite, galena and sulfide ions
}

\author{
YASUHIRO KIYOSU \\ Department of Earth Sciences, Faculty of Science, \\ Nagoya University, Chikusa, Nagoya 464, Japan \\ (Received August 7, 1973; in revised form September 7, 1973)
}

\begin{abstract}
Sulfur isotope fractionation in $\mathrm{ZnS}-\mathrm{HS}^{-}$and $\mathrm{PbS}-\mathrm{HS}^{-}$systems has been studied experimentally in the temperature range from 50 to $340^{\circ} \mathrm{C}$. Sulfur isotopic exchange between sulfide minerals and $\mathrm{HS}^{-}$ions was found to be unexpectedly fast. In the $\mathrm{ZnS}-\mathrm{HS}^{-}$system several ten hours are enough to attain isotopic equilibrium in the temperature range from 50 to $200^{\circ} \mathrm{C}$. Temperature dependence of equilibrium fractionation was estimated as follows:
\end{abstract}

$$
\begin{aligned}
& \text { 1n } \alpha_{\text {sphalerite-HS }}=111 T^{-2}+0.00136 \\
& \ln \alpha_{\text {galena-HS }}=-782 T^{-2}+0.00170
\end{aligned}
$$

From these equations the temperature dependence of sphalerite-galena fractionation is

$$
\text { ln } \alpha_{\text {sphalerite-galena }}=891 T^{-2}-0.00057 \text {. }
$$

\section{INTRODUCTION}

Sulfur isotopic fractionation between sulfide minerals has recently been studied by several researchers. SAKAI (1968) has theoretically estimated sulfur isotopic fractionations among pyrite, sphalerite and galena from spectroscopic data. Experimental estimations also have been carried out by GrootenBore and SCHWARCZ (1969) using sphalerite - sulfur and galena - sulfur pairs at temperatures from 340 to $690^{\circ} \mathrm{C}$; by KaJiWARA et al. (1969) and KAJIWARA and Krouse (1971) using the sphalerite galena system, in which sulfur isotopic fractionation factors between sulfide minerals were estimated through sulfur vapor at temperatures from 150 to $630^{\circ} \mathrm{C}$; and by RYE and CZAMANSKI (1969) using a recrystallization technique for zinc and lead sulfides under hydrothermal conditions. These results, however, do not agree well with each other. The present study, therefore, intends to re-examine the sulfur isotopic fractionation between sphalerite and galena. Since it seemed difficult to establish the sulfur isotopic exchange equilibrium between sphalerite and galena under hydrothermal conditions, the equilibration experiment is primarily carried out for the sphalerite $\mathrm{HS}^{-}$ion and galena - $\mathrm{HS}^{-}$ion pairs at temperatures from 50 to $340^{\circ} \mathrm{C}$ and then the 
estimate of equilibrium fractionation for the sphalerite - galena pair is made by combining the experimental results for the sphalerite $-\mathrm{HS}^{-}$ion and galena $-\mathrm{HS}^{-}$ion systems.

\section{ExPERIMENTAL AND RESUlts}

Sulfur isotopic equilibrium fractionation factors for the zinc sulfide - sulfide ion and lead sulfide - sulfide ion pairs were studied by the partial exchange technique (NorThrop and Clayton, 1966).

Sulfides used in this isotopic fractionation experiment were prepared and analyzed as follows:

Hydrogen sulfide solutions

Three hydrogen sulfide solutions of different sulfur isotopic ratios were prepared. $\mathrm{L}_{1}$ : Reagent grade sodium sulfide was dissolved in water. $L_{2}$ and $L_{3}$ : Two isotopically different $\mathrm{H}_{2} \mathrm{~S}$ gases were absorbed in $1 \mathrm{~N} \mathrm{NaOH}$ solution under argon atmosphere. These two hydrogen sulfide gases used were prepared by decomposing reagent barium sulfide and iron sulfide with concentrated hydrochloric acid. The sulfur content of these solutions was determined by iodometry. The $\mathrm{pH}$ and isotopic composition of these hydrogen sulfide solutions are summarized in Table 1.

Table 1. Isotopic composition of the starting materials

\begin{tabular}{|c|c|c|c|c|}
\hline \multicolumn{2}{|c|}{ Starting materials } & $\delta^{34} \mathrm{~S}, \%$ & $\mathrm{pH}$ & $\mathrm{S}, \mathrm{mol} / 1$ \\
\hline \multicolumn{5}{|c|}{ Hydrogen sulfide } \\
\hline $\mathrm{L}_{1}$ & & +2.3 & 9.9 & 0.84 \\
\hline $\mathrm{L}_{2}$ & & +9.4 & 10.0 & 0.88 \\
\hline $\mathrm{L}_{3}$ & & -5.4 & 10.2 & 0.59 \\
\hline \multicolumn{5}{|c|}{ Sulfide samples } \\
\hline sphalerite & No.1 & +2.6 & & \\
\hline sphalerite & No. 2 & +9.6 & & \\
\hline galena & No.1 & +2.3 & & \\
\hline galena & No. 2 & +9.4 & & \\
\hline
\end{tabular}

Zinc and lead sulfides

Two isotopically different zinc sulfides were prepared from $10 \%$ zinc acetate solution and $0.8 \mathrm{M} \mathrm{NaHS}$ solutions $\left(\mathrm{L}_{1}\right.$ and $\left.\mathrm{L}_{2}\right)$ by the usual method, and lead sulfides from $10 \%$ lead acetate solution and $0.8 \mathrm{M} \mathrm{NaHS}$ solutions $\left(\mathrm{L}_{1}\right.$ and $\left.\mathrm{L}_{2}\right)$.

Equilibration Five $\mathrm{ml}$ of NaHS solution and $40 \mathrm{mg}$ of zinc sulfide or $100 \mathrm{mg}$ of lead sulfide were placed in a glass tube, $19 \mathrm{~mm}$ in inside diameter and $120 \mathrm{~mm}$ in length. At temperatures above $100^{\circ} \mathrm{C}$, a gold tube of $16 \mathrm{~mm}$ inside diameter and $100 \mathrm{~mm}$ length was inserted into a glass tube, and the starting materials were placed in the gold tube, because NaHS solution attacks glass at higher temperatures. The 
glass tube was sealed after evacuation, and put into a constant temperature water bath. After desired equilibration time, the glass tube was cooled with cold water to quench sulfur isotopic exchange reaction. In higher temperature experiments, the tube was heated in an autoclave, and sulfur isotopic exchange reaction was quenched by cooling the reaction vessel with air from an electric fan and then with cold water.

Isotopic analyses $\quad \mathrm{The} \mathrm{ZnS}$ and $\mathrm{PbS}$ samples were treated with $6 \mathrm{~N} \mathrm{HCl}$ to evolve hydrogen sulfide. The evolved hydrogen sulfide gas was collected as CdS, and then converted to $\mathrm{Ag}_{2} \mathrm{~S}$. Sulfide ions were also collected as CdS by the addition of cadmium acetate to the solution and then converted to $\mathrm{Ag}_{2} \mathrm{~S}$. The $\mathrm{Ag}_{2} \mathrm{~S}$ samples obtained were burnt to sulfur dioxide in a stream of $\mathrm{CO}_{2}$-free air at $1,200^{\circ} \mathrm{C}$. The resulted sulfur dioxide was analyzed for ${ }^{34} \mathrm{~S}$ on a double-collector mass spectrometer (Varian Mat $\mathrm{CH7).} \mathrm{The} \mathrm{isotopic} \mathrm{data} \mathrm{obtained} \mathrm{were} \mathrm{given} \mathrm{in} \mathrm{terms} \mathrm{of} \delta^{34} \mathrm{~S}$ value relative to the troilite sulfur of Canyon Diablo meteorite.

$$
\delta^{34} \mathrm{~S}(\%)=\left[\left({ }^{34} \mathrm{~S} /{ }^{32} \mathrm{~S}\right)_{\text {sample }} /\left({ }^{34} \mathrm{~S} /{ }^{32} \mathrm{~S}\right)_{\text {std. }}-1\right] \times 1000
$$

The reproducibility of isotopic measurements was $\pm 0.2 \%$.

Sulfur isotopic exchange reaction between metallic sulfide and $\mathrm{HS}^{-}$ions can be represented by

$$
\mathrm{M}^{34} \mathrm{~S}+\mathrm{H}^{32} \mathrm{~S}^{-}=\mathrm{M}^{32} \mathrm{~S}+\mathrm{H}^{34} \mathrm{~S}^{-}
$$

The isotopic fractionation factor for this system is

$$
\begin{aligned}
\alpha \mathrm{MS}_{-} \mathrm{HS}^{-} & =\left({ }^{34} \mathrm{~S} /{ }^{32} \mathrm{~S}\right)_{\mathrm{MS}} /\left({ }^{34} \mathrm{~S} /{ }^{32} \mathrm{~S}\right)_{\mathrm{HS}^{-}} \\
& =\left[1+\left(\delta^{34} \mathrm{~S}_{\mathrm{MS}} / 1000\right)\right] /\left[1+\left(\delta^{34} \mathrm{~S}_{\mathrm{HS}^{-}} / 1000\right)\right]
\end{aligned}
$$

The fractionation factors for the zinc sulfide - $\mathrm{HS}^{-}$and lead sulfide - $\mathrm{HS}^{-}$pairs were estimated from the results given in Tables 2 and 3, respectively, by the partial exchange method (NorThrop and CLAYTON, 1966), on the assumption that isotopic exchange reaction between metallic sulfide and $\mathrm{HS}^{-}$ions approaches equilibrium at a constant rate at a given temperature. The fractionation factor $\alpha_{\mathrm{MS}-\mathrm{HS}^{-}}$can be obtained by the following equation.

$$
\ln \alpha_{\mathrm{i}}=\ln \alpha_{\mathrm{MS}-\mathrm{HS}^{-}}+\mathrm{A}\left(\ln \alpha_{\mathrm{f}}-\ln \alpha_{\mathrm{i}}\right)
$$

Where $\alpha_{\mathbf{i}}$ is the initial isotopic fractionation between metallic sulfide and HS $^{-}$ions, $\alpha_{\mathrm{f}}$ is the final fractionation in the partial equilibrium state between metallic sulfide and $\mathrm{HS}^{-}$ions, and $\mathrm{A}$ is constant. 
Table 2. Fractionation experiments in the system galena-sulfide ions

\begin{tabular}{|c|c|c|c|c|c|c|c|c|c|c|}
\hline \multirow{2}{*}{$\begin{array}{l}\text { Run } \\
\text { No. }\end{array}$} & \multirow{2}{*}{$\begin{array}{l}\mathrm{T} \\
{ }^{\circ} \mathrm{C}\end{array}$} & \multirow{2}{*}{$\begin{array}{c}\text { Time } \\
\text { hr. }\end{array}$} & \multicolumn{2}{|c|}{$\delta^{34} S_{g n}, \%$} & \multicolumn{2}{|c|}{$\delta^{34} \mathrm{~S}_{\mathrm{HS}}, \%$} & \multicolumn{2}{|c|}{$1,000 \ln \alpha$} & \multirow{2}{*}{$\begin{array}{c}1,000\left(\ln \alpha_{\mathrm{f}}\right. \\
\left.-\ln \alpha_{\mathrm{i}}\right)\end{array}$} & \multirow{2}{*}{$\begin{array}{c}1,000 \ln \alpha \\
\text { Equil. }\end{array}$} \\
\hline & & & Ini. & Fin. & Ini. & Fin. & Ini. & Fin. & & \\
\hline$x-22$ & 101 & 233 & +2.3 & -4.1 & -5.4 & -4.6 & +7.7 & +0.5 & -7.2 & \\
\hline 21 & 101 & 233 & +2.3 & +4.8 & +9.4 & +10.7 & -7.1 & -5.9 & +1.2 & -3.8 \\
\hline 22 & 101 & 233 & +9.4 & +5.8 & +2.3 & +2.9 & +7.1 & +2.9 & -4.2 & \\
\hline 23 & 101 & 233 & +9.4 & +2.5 & -5.4 & -4.4 & +14.8 & +6.9 & -7.9 & \\
\hline 09 & 200 & 49 & +2.3 & -4.4 & -5.4 & -4.6 & +7.7 & +0.2 & -7.5 & \\
\hline 18 & 200 & 49 & +2.3 & +6.8 & +9.4 & +9.9 & -7.1 & -4.9 & +3.1 & -2.2 \\
\hline 11 & 200 & 49 & +9.4 & +4.9 & +2.3 & +2.7 & +7.1 & +2.2 & -4.9 & \\
\hline 12 & 200 & 49 & +9.4 & -0.4 & -5.4 & -4.3 & +14.8 & +3.9 & -10.9 & \\
\hline 13 & 250 & 30 & +2.3 & -5.0 & -5.4 & -4.6 & +7.7 & -0.4 & -8.1 & \\
\hline 19 & 250 & 30 & +2.3 & +6.8 & +9.4 & +9.9 & -7.1 & -3.1 & +4.0 & -1.3 \\
\hline 15 & 250 & 30 & +9.4 & +5.0 & +2.3 & +2.8 & +7.1 & +2.2 & -4.9 & \\
\hline 16 & 250 & 30 & +9.4 & -1.8 & -5.4 & -4.0 & +14.8 & +2.2 & -12.6 & \\
\hline 05 & 300 & 24 & +2.3 & -5.5 & -5.4 & -4.5 & +7.7 & -1.0 & -8.7 & \\
\hline 17 & 300 & 24 & +2.3 & +7.3 & +9.4 & +9.7 & -7.1 & -2.4 & +4.7 & -0.3 \\
\hline 07 & 300 & 24 & +9.4 & +2.7 & +2.3 & +2.4 & +7.1 & +0.3 & -6.8 & \\
\hline 08 & 300 & 24 & +9.4 & -3.0 & -5.4 & -4.1 & +14.8 & +1.1 & -13.7 & \\
\hline 24 & 340 & 10 & +2.3 & -5.4 & -5.4 & -4.3 & +7.7 & -1.1 & -8.8 & \\
\hline 25 & 340 & 10 & +2.3 & +7.2 & +9.4 & +9.6 & -7.1 & -2.4 & +4.7 & \\
\hline 26 & 340 & 10 & +9.4 & +3.6 & +2.3 & +1.6 & +7.1 & +2.0 & -5.1 & \\
\hline
\end{tabular}

Table 3. Fractionation experiments in the system sphalerite-sulfide ions

\begin{tabular}{|c|c|c|c|c|c|c|c|c|c|c|}
\hline \multirow{2}{*}{$\begin{array}{l}\text { Run } \\
\text { No. }\end{array}$} & \multirow{2}{*}{$\begin{array}{l}\mathrm{T} \\
{ }^{\circ} \mathrm{C}\end{array}$} & \multirow{2}{*}{$\begin{array}{l}\text { Time } \\
\text { hr. }\end{array}$} & \multirow{2}{*}{\multicolumn{2}{|c|}{$\begin{array}{c}\delta^{34} \mathrm{~S}_{\text {sp, }} \%{ }_{00} \\
\text { Ini. } \quad \text { Fin. }\end{array}$}} & \multicolumn{2}{|c|}{$\delta^{34} \mathrm{~S}_{\mathrm{HS}^{-}}, \% 0$} & \multicolumn{2}{|c|}{$1,000 \ln \alpha$} & \multirow{2}{*}{$\begin{array}{c}1,000\left(\ln \alpha_{\mathrm{f}}\right. \\
\left.-\ln \alpha_{\mathbf{i}}\right)\end{array}$} & \multirow{2}{*}{$\begin{array}{c}1,000 \ln \alpha \\
\text { Equil. }\end{array}$} \\
\hline & & & & & Ini. & Fin. & Ini. & Fin. & & \\
\hline$Y-45$ & 50 & 13 & +2.6 & -1.1 & -5.4 & -4.9 & +8.0 & +3.8 & -4.2 & \\
\hline 46 & 50 & 13 & +2.6 & +11.1 & +9.4 & +8.4 & -6.8 & +2.7 & +9.5 & +3.5 \\
\hline 47 & 50 & 13 & +9.6 & +5.9 & +2.3 & +2.6 & +7.3 & +3.3 & -4.0 & \\
\hline 48 & 50 & 13 & +9.6 & +0.6 & -5.4 & -4.6 & +15.0 & +5.2 & -9.8 & \\
\hline 33 & 78 & 59 & +2.6 & -2.6 & -5.4 & -5.1 & +8.0 & +2.5 & -5.5 & \\
\hline 34 & 78 & 59 & +2.6 & +10.9 & +9.4 & +8.8 & -6.8 & +2.1 & +8.9 & +2.6 \\
\hline 35 & 78 & 59 & +9.6 & +5.3 & +2.3 & +2.7 & +7.3 & +2.6 & -4.7 & \\
\hline 36 & 78 & 59 & +9.6 & -0.9 & -5.4 & -4.9 & +15.0 & +4.0 & -11.0 & \\
\hline 41 & 97 & 43 & +2.6 & -2.7 & -5.4 & -4.8 & +8.0 & +2.1 & -5.9 & \\
\hline 42 & 97 & 43 & +2.6 & +11.0 & +9.4 & +8.4 & -6.8 & +2.6 & +9.4 & +2.0 \\
\hline 43 & 97 & 43 & +9.6 & +3.6 & +2.3 & +2.7 & +7.3 & +0.9 & -6.4 & \\
\hline 44 & 97 & 43 & +9.6 & -1.1 & -5.4 & -4.4 & +15.0 & +3.3 & -11.7 & \\
\hline 25 & 100 & 120 & +2.6 & -2.7 & -5.4 & -4.7 & +8.0 & +2.0 & -6.0 & \\
\hline 26 & 100 & 120 & +2.6 & +9.9 & +9.4 & +9.2 & -6.8 & +0.7 & +7.5 & +1.7 \\
\hline 27 & 100 & 120 & +9.6 & +4.5 & +2.3 & +3.0 & +7.3 & +1.5 & -5.8 & \\
\hline 28 & 100 & 120 & +9.6 & -1.5 & -5.4 & -4.2 & +15.0 & +2.7 & -12.3 & \\
\hline 37 & 150 & 6 & +2.6 & -1.5 & -5.4 & -5.2 & +8.0 & +3.7 & -4.3 & \\
\hline 38 & 150 & 6 & +2.6 & +8.8 & +9.4 & +8.7 & -6.8 & +0.1 & +6.9 & +1.8 \\
\hline 39 & 150 & 6 & +9.6 & +4.9 & +2.3 & +2.7 & +7.3 & +2.2 & -5.1 & \\
\hline 40 & 150 & 6 & +9.6 & -0.2 & -5.4 & -4.6 & +15.0 & +4.4 & -10.6 & \\
\hline 13 & 200 & 48 & +2.6 & -2.9 & -5.4 & -4.6 & +8.0 & +1.7 & -6.3 & \\
\hline 14 & 200 & 48 & +2.6 & +9.3 & +9.4 & +8.6 & -6.8 & +0.7 & +7.5 & +1.3 \\
\hline 15 & 200 & 48 & +9.6 & +4.4 & +2.3 & +3.0 & +7.3 & +1.4 & -5.9 & \\
\hline 16 & 200 & 48 & +9.6 & -2.0 & -5.4 & -3.8 & +15.0 & +1.8 & -13.2 & \\
\hline 17 & 250 & 29 & +2.6 & -2.3 & -5.4 & -4.6 & +8.0 & +2.3 & -5.7 & \\
\hline 18 & 250 & 29 & +2.6 & +10.1 & +9.4 & $\begin{array}{r}+8.4 \\
\end{array}$ & -6.8 & +1.7 & +8.5 & +1.8 \\
\hline
\end{tabular}




\begin{tabular}{lcrrrrrrrrr}
\hline \hline Run & \multicolumn{1}{c}{$\mathrm{T}$} & Time & \multicolumn{2}{c}{$\delta^{34} \mathrm{~S}_{\mathrm{sp}} \% \%$} & \multicolumn{2}{c}{$\delta^{34} \mathrm{~S}_{\mathrm{HS}}, \% 0$} & \multicolumn{2}{c}{$1,000 \ln \alpha$} & $1,000\left(\ln \alpha_{\mathrm{f}}\right.$ & $1,000 \ln \alpha$ \\
No. & ${ }^{\circ} \mathrm{C}$ & \multicolumn{1}{c}{ hr. } & \multicolumn{1}{c}{ Ini. } & Fin. & Ini. & Fin. & Ini. & Fin. & $\left.-\ln \alpha_{\mathrm{i}}\right)$ & Equil. \\
\hline $\mathrm{Y}-19$ & 250 & 29 & +9.6 & +4.2 & +2.3 & +2.7 & +7.3 & +1.5 & -5.8 & \\
20 & 250 & 29 & +9.6 & -2.5 & -5.4 & -3.8 & +15.0 & +1.3 & -13.7 & \\
21 & 300 & 4 & +2.6 & -3.5 & -5.4 & -4.8 & +8.0 & +1.3 & -6.7 & \\
22 & 300 & 4 & +2.6 & +9.8 & +9.4 & +8.2 & -6.8 & +1.6 & +8.4 & +1.4 \\
23 & 300 & 4 & +9.6 & +4.1 & +2.3 & +2.8 & +7.3 & +1.3 & -6.0 & \\
24 & 300 & 4 & +9.6 & -2.9 & -5.4 & -3.7 & +15.0 & +0.8 & -14.2 & \\
\hline
\end{tabular}

\section{DisCUSSION}

Hydrogen sulfide in aqueous solution dissociates as follows:

$$
\begin{aligned}
& \mathrm{H}_{2} \mathrm{~S}=\mathrm{H}^{+}+\mathrm{HS}^{-} \\
& \mathrm{HS}^{-}=\mathrm{H}^{+}+\mathrm{S}^{=}
\end{aligned}
$$

In low $\mathrm{pH}$ ranges aqueous sulfide is present dominantly as $\mathrm{H}_{2} \mathrm{~S}$, and in high $\mathrm{pH}$ ranges as $\mathrm{S}^{=}$(e.g.; Ellis and Milestone, 1967; Ellis and Giggenbach 1971). Under the present experimental conditions, however, the predominant sulfur species is believed to be $\mathrm{HS}^{-}$. Therefore, the sulfur isotopic fractionations observed in the present work must be those between $\mathrm{ZnS}$ and $\mathrm{HS}^{-}$and $\mathrm{PbS}$ and $\mathrm{HS}^{-}$.

Galena-HS $S^{-}$ion system A linear relationship between $\ln \alpha_{\mathrm{i}}$ and $\ln \alpha_{\mathrm{f}}-\ln \alpha_{\mathrm{i}}$ was obtained at each experimental temperature. Figure 1 shows the results, for example, at 100 and $300^{\circ} \mathrm{C}$. The intersections of these lines with the ordinate indicate equilibrium fractionation factors. The equilibrium fractionation factors obtained are all negative. In other words, $\mathrm{HS}^{-}$ions are more enriched in ${ }^{34} \mathrm{~S}$ than is galena. The equilibrium fractionation factors thus obtained can be fitted by a straight line on the $\ln \alpha v$. $T^{-2}$ plot (Fig. 2) and is represented by the following equation:

$$
\ln \alpha=-782 T^{-2}+0.00170
$$

This equation agrees well with SAKaI's theoretical data (1968).

Sphalerite - $H S^{-}$ion system A straight line was obtained on the $\ln \alpha_{\mathrm{i}} v s . \ln \alpha_{\mathrm{f}}$ $\ln \alpha_{i}$ plot at each experimental temprature as shown in Fig.1, for example. The intersections of the lines with the ordinate indicate that sphalerite is enriched in ${ }^{34} \mathrm{~S}$ relative to $\mathrm{HS}^{-}$ions. The temperature dependence of the fractionation factor for this system derived by the least-squares method is given by the following equation (Fig.2):

$$
\ln \alpha=111 T^{-2}+0.00136
$$

The scatter for this experiment is larger than that of galena - $\mathrm{HS}^{-}$ion system, because 


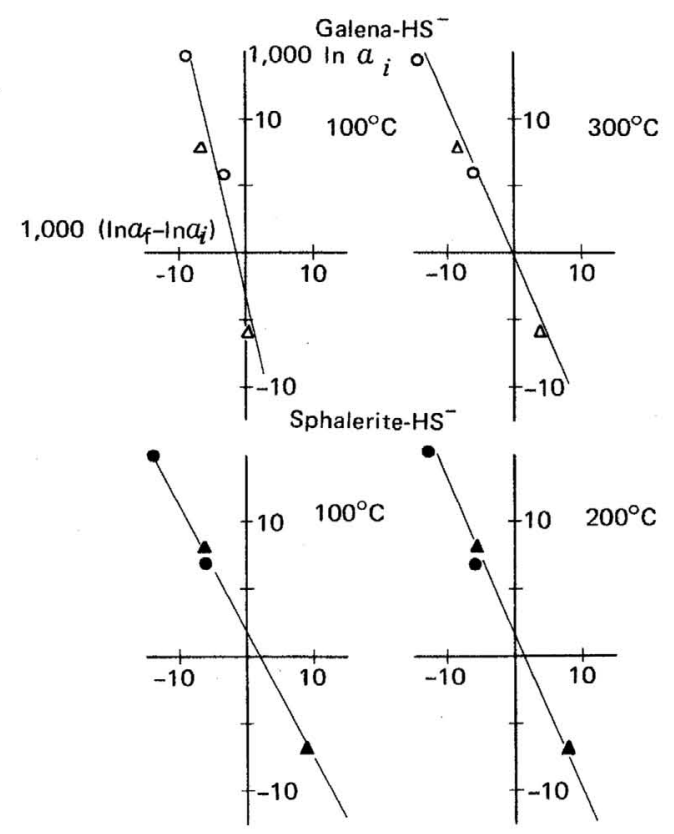

Fig.1. Determination of isotopic fractionations for the sphalerite-HS ${ }^{-}$and galena-HS ${ }^{-}$pairs by the partial exchange method. Open circles and triangles represent Nos.1 and 2 galena samples, respectively. Solid circless and triangles represent Nos.1 and 2 sphalerite samples, respectively.

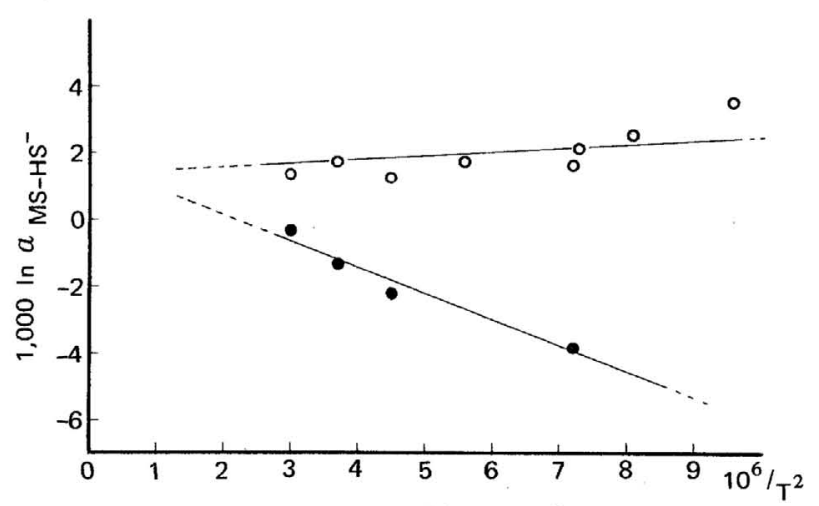

Fig.2. Spahlerite-HS ${ }^{-}$ion and galena-HS ${ }^{-}$ion fractionation curves. Open and solid circles indicate the fractionations for the sphalerite- $\mathrm{HS}^{-}$and galena$\mathrm{HS}^{-}$systems, respectively.

the exchange rate is so fast that re-equilibration occurs as the glass tube is being cooled. 
Isotopic exchange rate

Isotopic exchange rates were calculated by assuming a first order reaction using the following equation:

$$
\ln (1-f)=-K t
$$

where $f$ is the fraction of sulfur isotopes exchanged, $K$ is the constant of exchange rate, and $t$ is time. The exchange rate constant and the half-time of isotopic exchange obtained for the sphalerite $-\mathrm{HS}^{-}$ion and galena $-\mathrm{HS}^{-}$ion systems are given in Table 4 . The exchange rates observed are unexpectedly fast. It is therefore suggested that the isotopic exchange equilibrium between sphalerite and galena may be soon attained in the oreforming solution in which the predominant sulfur species is $\mathrm{HS}^{-}$ions.

Table 4. Isotopic exchange rates in the systems galena-sulfide ions, sphalerite-sulfide ions

\begin{tabular}{ccccccc}
\hline \hline & $T,{ }^{\circ} \mathrm{C}$ & Time, hr. & $f$ & \multicolumn{1}{c}{$K, \mathrm{hr}^{-1}$} & $\log t_{1 / 2}, \mathrm{hr}$. \\
\hline PbS-HS & 300 & 24 & 0.81 & $1.31 \times 10^{-2}$ & 1.00 \\
$"$ & 250 & 30 & 0.78 & $9.52 \times 10^{-3}$ & 1.14 \\
$"$ & 200 & 49 & 0.64 & $3.93 \times 10^{-3}$ & 1.52 \\
$"$ & 101 & 233 & 0.48 & $5.29 \times 10^{-4}$ & 2.39 \\
ZnS-HS & 150 & 6 & 0.81 & $5.22 \times 10^{-2}$ & 0.40 \\
$"$ & 97 & 43 & 0.99 & $2.32 \times 10^{-2}$ & 0.75 \\
$"$ & 78 & 59 & 0.93 & $1.12 \times 10^{-2}$ & 1.06 \\
$"$ & 50 & 13 & 0.90 & $3.35 \times 10^{-2}$ & 0.59 \\
\hline
\end{tabular}

Sphalerite - galena fractionation

The equilibrium isotopic fractionation factor for the sphalerite - galena pair can be obtained from the equation for the sphalerite $\mathrm{HS}^{-}$ion and galena - $\mathrm{HS}^{-}$ion pairs as follows:

$$
\ln \alpha_{\text {sphalerite-galena }}=891 T^{-2}-0.00057
$$

Figure 3 shows the sphalerite - galena curves obtained by the present work, KAJIWARA and Krouse (1971), and RYE and CzamansKi (1969). It is seen that the curve obtained by the present work is closer to that reported by KAJIWARA and KROUSE (1971) than to that by RYE and Czamanski (1969) at temperatures below $400^{\circ} \mathrm{C}$.

By using equation (10) and sulfur isotopic fractionation data for coexisting sphalerite and galena samples from the Taishu and Toyoha mines, Japan, (KIYosu, unpublished data) and the Upper Mississippi valley zinc - lead ore deposits in North America, (PINCKNEY and RAFTER, 1972), isotopic temperatures are estimated as shown in Fig.4. The agreement of isotopic temperatures with fluid inclusion temperatures is good for Taishu and Upper Mississippi valley deposits (TAKENOUCHI, 1962; PInCKney and RAFTER, 1972), but not for Toyoha deposits (YAJIMA and OKABE, 1970), as seen in Fig.4. At Toyoha, the exact contemporaneity between the sulfide pairs examined and/or between the sulfides and quartz from which the fluid inclusion temperature was estimated is doubtful. 


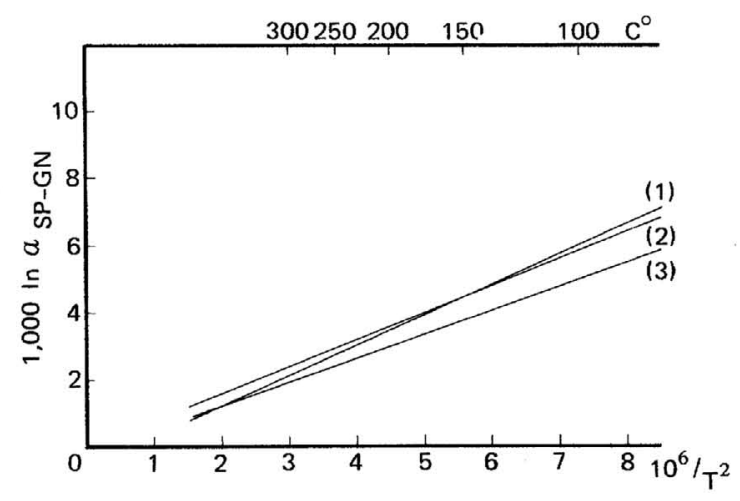

Fig.3. Sulfur isotope fractionation curves for the sphalerite-galena system. Curve (1): This work, curve (2): KAJIWARA and KROUSE (1971), and curve (3): RYE and CZAMANSKI (1969).

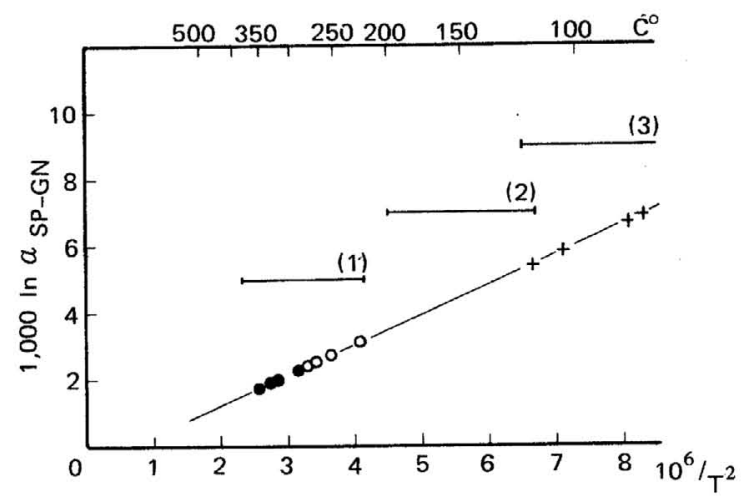

Fig.4. Isotopic temperatures of coexisting sphalerite and galena from natural ore deposits.

- : Taishu mine, Japan; $\bigcirc$ : Toyoha mine, Japan; (KIYOSU, unpublished data), + : Upper Mississippi valley zinc-lead ore deposits, (PINCKNEY and RAFTER, 1971).

$\mapsto$ : Filling temperatures of fluid inclusion; (1) Taishu mine, TAKENOUCHI (1969), (2) Toyoha mine, YaJIMA (1970), (3) Upper Mississippi valley deposits, PINCKNEY and RAFTER (1971).

\section{ConcLusion}

(1) Sulfur isotopic fractionation experiments yielded the following relationships:

$$
\begin{aligned}
& \left.\ln \alpha=111 T^{-2}+0.00136 \text { (sphalerite }-\mathrm{HS}^{-}\right) \\
& \left.\ln \alpha=-782 T^{-2}+0.00170 \text { (galena }-\mathrm{HS}^{-}\right) \\
& \ln \alpha=891 T^{-2}-0.00057 \quad \text { (sphalerite - galena) }
\end{aligned}
$$


(2) Sulfur isotopic exchange between sulfide minerals and $\mathrm{HS}^{-}$ions was found to be fast.

(3) The temperatures of formation of Taishu and Upper Mississippi valley deposits estimated from the isotopic fractionation between sphalerite and galena agreed with those estimated by the fluid inclusion studies.

\section{ACKNOWLEDGMENTS}

The author would like to acknowledge the continuing advice and encouragement of Dr. N. NAKaI of Nagoya University. The author is also deeply indebted to Prof. S. OANA and Dr. Y. MIZUTANI of Nagoya University for helpful suggestions and a critical reading of the manuscript.

\section{REFERENCES}

Ellis, A. J. and Milestone, N. B. (1967) The ionization constants of hydrogen sulphide from 20 to $90^{\circ} \mathrm{C}$. Geochim. Cosmochim. Acta 31, 615-620.

Ellis, A. J. and GigGENBACH, W. (1971) Hydrogen sulphide ionization and sulphur hydrolysis in high temperature solution. ibid. 35, 247-260.

Grootenbore, J. and SCHWARCZ, H. P. (1969) Temperature dependent sulfur isotope fractionation between sulfide minerals. Earth Planet. Sci. Letters 7, 162-166.

KaJiwara, Y., Krouse, H. R. and SASAKI, A. (1969) Experimental study of sulfur isotope fractionation between coexistent sulfide minerals. ibid. 7, 271-277.

KAJIWARA, Y. and KROUSE, H. R. (1971) Sulfur isotope partitioning in metallic sulfide systems. Canad. J. Earth Sci. 8, 1397-1408.

Northrop, D. A. and Clayton, R. N. (1966) Oxygen-isotope fractionation in systems containing dolomite. J. Geol. 74, 174-196.

PinCKNEY, D. M. and RAFTER, T. A. (1972) Fractionation of sulfur isotopes during ore deposition in the Upper Mississippi Valley Zinc-Lead District. Econ. Geol. 67, 315-328.

RYE, R. O. and CZAMANSKI, G. K. (1969) Experimental determination of sphalerite-galena sulfur isotope fractionation and applications to the ores at Providencia, Mexico. Ann. Mtgs. Geol. Soc. Am. (abs.) 195.

SAKAI, H. (1968) Isotopic properties of sulfur compounds in hydrothermal processes. Geochem. J. 2, 29-49.

TAKENOUCHI, S. (1962) Polyphase inclusions in the quartz from the Taishu mine, Nagasaki Prefecture. Mining Geol. (Tokyo), 12, 294-297 (in Japanese).

YAJIMA, J. and OKABE, K. (1970) On the iron-rich banded ore from the Toyoha mine, Hokkaido, Japan. ibid. 21, 221-228 (in Japanese). 